\title{
Factors associated with tuberculosis by HIV status in the Brazilian national surveillance system: a cross sectional study
}

\author{
Thiago Nascimento do Prado 1,2,3, Angélica Espinosa Miranda³,4, Fernanda Mattos de Souza', \\ Elias dos Santos Dias ${ }^{1,2}$, Lorena Kellen Fernandes Sousa ${ }^{1,2}$, Denise Arakaki-Sanchez ${ }^{5}$, Mauro N Sanchez ${ }^{6}$, \\ Jonathan E Golub ${ }^{7}$ and Ethel Leonor Maciel ${ }^{1,2,3,4^{*}}$
}

\begin{abstract}
Background: Over the last decade tuberculosis (TB) incidence and mortality in Brazil have been steadily declining. However, this downward trend has not been observed among HIV-infected patients. We describe the epidemiological and clinical profile of TB patients by HIV status using the Brazilian National Surveillance System.

Methods: All TB diagnoses with HIV status information between January 1, 2007 and December 31, 2011 were categorized as either HIV or non-HIV at time of TB diagnosis. Co-infected patients (TB-HIV) were compared to TB patients with no HIV-infection using a hierarchical logistic regression model using Stata 13.0.

Results: The prevalence of TB-HIV co-infection was 19\% among adults $\geq 15$ years of age. We analyzed data from 243,676 individuals, of whom 46,466 were TB-HIV and 197,210 were only TB cases. The following factors increased risk of co-infection: male sex (OR: 1.06, 95\% Cl 1.03-1.10), 20 to 39 years of age $(\mathrm{OR}=4.82,95 \% \mathrm{Cl}$ 4.34-5.36), black (OR=1.08, $95 \% \mathrm{Cl} 1.04-1.13), 4-7$ years of education ( $\mathrm{OR}=1.13,95 \% \mathrm{Cl} 1.19-1.28)$, diagnosed following default $(\mathrm{OR}=2.65,95 \% \mathrm{Cl}$ 1.13-6.25), presenting with pulmonary and extra-pulmonary forms of TB simultaneously ( $\mathrm{OR}=2.80,95 \% \mathrm{Cl} 1.56-5.02)$, presenting with histopathologic examination suggestive of $\mathrm{TB}(\mathrm{OR}=2.15,95 \% \mathrm{Cl} 1.13-4.07)$. Co-infected patients were less likely to live in rural areas $(O R=0.45,95 \% \mathrm{Cl} 0.42-0.48)$, have diabetes $(O R=0.45,95 \% \mathrm{Cl} 0.40-0.50)$ and be smear positive $(\mathrm{OR}=0.55,95 \% \mathrm{Cl} 0.32-0.95)$, and co-infected patients had higher risk of default $(\mathrm{OR}=2.96$, 95\% Cl 2.36-3.71) and death from TB $(\mathrm{OR}=5.16,95 \% \mathrm{Cl} 43.04-5.77)$.

Conclusions: The prevalence of co-infection with HIV among TB patients is 19\% in Brazil. By identifying predictors of co-infection targeted interventions can be developed to prevent both TB and HIV, and to diagnose each disease earlier and ultimately decrease poor treatment outcomes and death.
\end{abstract}

Keywords: Tuberculosis, HIV, Coinfection, Logistic regression

\section{Background}

Tuberculosis (TB) remains a serious public health problem, especially in developing countries like Brazil, which is one of the 22 high burden countries of the disease worldwide [1]. Over the last decade TB incidence and mortality in Brazil have been steadily declining. However, this downward trend has not been observed among HIV-infected patients [2,3].

\footnotetext{
* Correspondence: ethel.maciel@gmail.com

'Lab-Epi UFES - Laboratório de Epidemiologia, Universidade Federal do Espírito Santo, Av. Marechal Campos, 1468- Maruípe, Vitória, ES, Brazil

${ }^{2}$ School of Nursing, Federal University of Espírito Santo, Espírito Santo, Brazil Full list of author information is available at the end of the article
}

Since the 1980s, HIV has been one of the main factors contributing to the resurgence of TB in developed and developing countries alike [4]. The virus has changed the natural history of active tuberculosis as well as having a marked impact on the epidemiology and clinical outcomes of TB [5,6]. HIV infected patients have an annual risk of reactivating latent TB infection between 3 and $15 \%$ compared to 0.01 to $0.1 \%$ for the general population [7].

The implementation of collaborative TB-HIV activities is still modest in Brazil. These activities include coordination between the HIV/AIDS and TB programs for 
delivering integrated TB and HIV services including testing $\mathrm{TB}$ patients for HIV, providing ART to TB coinfected patients, providing HIV prevention services for TB patients, intensifying TB case finding among people living with HIV, and offering isoniazid preventive therapy. Tuberculosis in HIV-infected patients is often not identified until death, highlighting a failure of the health system to detect both diseases earlier [8]. A recent study of the six Brazilian states with the highest reported levels of HIV data in the Brazilian national TB reporting system, reported that $40 \%$ of TB patients had no HIV status provided [9].

Studies conducted in Brazil and other high burden TB countries have reported several socio-demographic and clinical features significantly associated with TB-HIV coinfection [10-12]. However, to the authors' knowledge, there has not been such a study done in Brazil using the Epidemiological Surveillance System. In addition, none of these studies used models of analysis using the hierarchical multivariable analysis, which can detect the factors associated with TB-HIV co-infection relative to TB only in Brazil.

In this study, we describe the epidemiological and clinical profile of TB patients by HIV status using the Brazilian National Surveillance System.

\section{Methods}

\section{Study design}

This is a cross sectional study utilizing the database of the national TB reporting system (SINAN/TB). SINAN was developed in the early 90s, with the objective of collecting and processing data on disease notification throughout the country. SINAN is the primary information system from which data are extracted for epidemiological analyses
[13]. This system is available in the website http://dtr2004. saude.gov.br/sinanweb [14]. Although for this particular study, data were obtained from the Tuberculosis National Program at the Ministry of Health in order to avoid replication and misclassification. These databases support the improvement of health care systems in Brazil by increasing the capacity of health care workers to make decisions based on accurate information.

\section{Study population}

The population of the study included TB cases aged $\geq$ 15 years reported in Brazil between January 12007 and December 31, 2011.

\section{Variables, data collection}

The following socio-demographic covariates were evaluated: age $(<20$ years, $20-39$ years, $40-59$ years and $\geq$ 60 years), gender (male, female), skin color (white, black, mixed and other (Asian and indigenous), school level ( $<4$ years, 4 to 7 years, $\geq 8$ years), area of residence (urban, rural or peri-urban) and whether the individual was institutionalized (no or yes). The presence of diabetes and alcoholism was included.

The covariates related to TB included the type of TB diagnosed during the study period, classified as 1) new TB case (no prior TB diagnoses), relapse (completed a previous TB treatment) or, 3) return after default (individuals that defaulted from a previous TB treatment regimen and returned to continue treatment). We also included site of $\mathrm{TB}$ at presentation (pulmonary, extra pulmonary, pulmonary + extra pulmonary), localization of extra-pulmonary TB, tuberculin skin test (positive if higher than $10 \mathrm{~mm}$ ), existence of chest X-ray suspicious for $\mathrm{TB}$, result of initial sputum smear test, result of

A total of 429,567 cases $\geq 15$ years of age were reported in SINAN between 2007 and 2011.

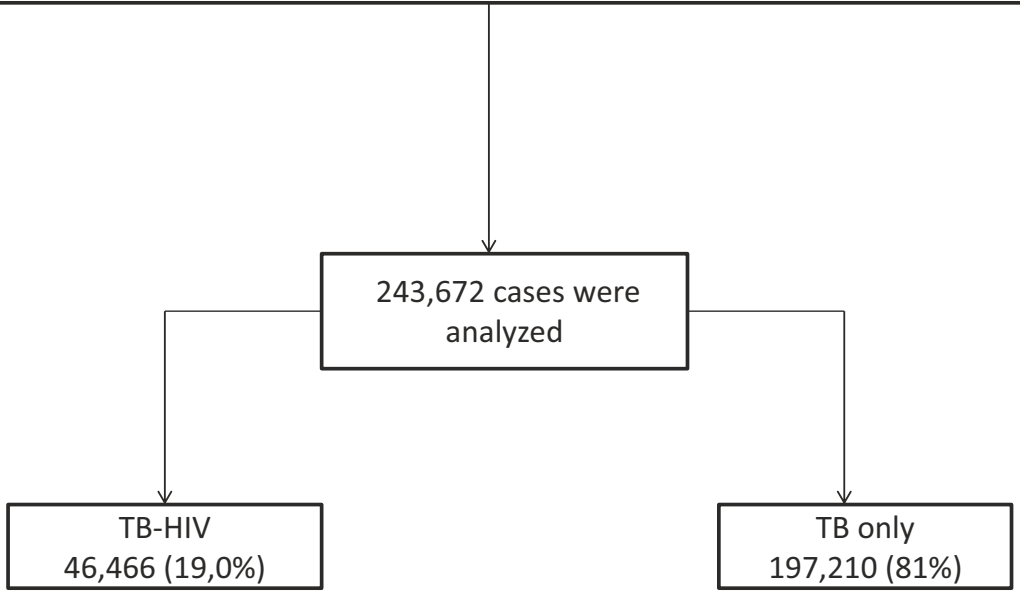

Figure 1 Study Flow Diagram; TB-HIV: Tuberculosis and HIV co-infection subjects; TB only: subjects who had only tuberculosis diseases. 
initial culture examination, and result of initial histopathologic examination. Receiving directly observed therapy (DOT) was also included as a covariate. Final treatment outcome was classified as cured (completed treatment and had at least two negative results of smear examination), default (those that did not attend to regular appointments for more than 30 days), TB death, other cause of death (died during TB treatment of another cause), transferred or developed MDR TB.

\section{Data analysis and statistics}

We compared individuals with TB and HIV (TB-HIV) with those who only had TB (TB only) according to socio-demographic and clinical characteristics. Pearson chi-square test was used to compare proportions. Covariates associated $(\mathrm{p} \leq 0.05)$ with the outcome of interest were included in a hierarchical logistic regression model.

Tuberculosis is a disease with a complex causal chain. Constructing a hierarchical model may be a better way to capture the interrelationships between its determinants. In this model, variables are included from distal to proximal ones, according to different levels of a causal network arising from a robust theoretical base [15,16]. Associations resulting from the hierarchical regression model are adjusted for the variables in the same level and those in previous levels, taking into account both confounders and mediators $[15,16]$.The present model was based on the conceptual framework for social determinants of TB formulated by Maciel [17]. In the hierarchical analysis, the following covariates were included: step 1 (Gender + age + school level + skin color + Area of residence); step 2 (variables retained from step $1+$ Institutionalization + DOT); step 3 (variables retained from step 2 Diabetes); step 4 (variables retained from step $3+$ treatment type + TB form + Tuberculin Skin Test + smear + culture + pathologic examination $+\mathrm{X}$ ray suspicious for TB); and step 5 (variables retained from step 4 + outcome). In each step, those covariates associated with the outcome $(\mathrm{p} \leq 0.05)$ were retained in the model. These analyses were conducted with Stata, version 13.0.

Due to the high proportion of missing information on HIV status, we carried out polynomial analysis based on the following $\mathrm{TB}$ treatment outcomes (cure, default, death from TB, death from other causes and MDR TB) comparing to HIV status (negative, positive, HIV test was requested and test not done). Cured TB status was used as a reference category instead of the present rendition.

\section{Ethics statement}

The databases were obtained under the rules for release of the Secretariat of Health Surveillance and Health Care Department of the Ministry of Health, ensuring the confidentiality and nondisclosure of individual identifiers. The Federal University of Espirito Santo (UFES) Institutional Review Board approved the study design by registration number 466/12.

\section{Results}

Between 2007 and 2011, 429,567 adult cases of TB were reported in SINAN, of which 185,891 (43.27\%) were missing data for HIV status. Among 243,676 TB patients with known HIV status, 46,466 (19\%) were TB-HIV co-infected (Figure 1).

Table 1 Distribution of socio-demographic characteristics of tuberculosis (TB) cases according to HIV status in Brazil, 2007-2011

\begin{tabular}{|c|c|c|}
\hline Characteristics $\left(\mathrm{N}^{*}\right)$ & $\begin{array}{l}\text { TB-HIV } \\
\text { n (\%) }\end{array}$ & $\begin{array}{c}\text { TB only } \\
\text { n (\%) }\end{array}$ \\
\hline
\end{tabular}

Gender $(243,670)$

$\begin{array}{lcccc}\text { Female } & 13,899(29.91) & 64,862(32.89) & <0,001 \\ \text { Male } & 32,567(70.09) & 132,342(67.11) & \\ \text { Age }(243,676) & & & \\ <20 \text { years } & 715(1.54) & 12,042(6.11) & <0,001 \\ \text { 20-39 years } & 26,610(57.27) & 94,448(47.89) & \\ \text { 40-59 years } & 17,554(37.78) & 67,495(34.22) & \\ \geq 60 \text { years } & 1,587(3.42) & 23,225(11.78) & \\ \text { Skin color }(225,264) & & & \\ \text { White } & 19,919(47.10) & 86,109(47.06) & <0,001 \\ \text { Black } & 6,716(15.88) & 23,432(12.81) & \\ \text { Browns } & 15,253(36.06) & 70,377(38.46) & \\ \text { Other } & 406(0.96) & 3,052(1.67)\end{array}$

School level $(123,482)$

$\begin{array}{lll}<4 \text { years } & 8,970(38.06) & 42,378(42.41) \\ 4-7 \text { years } & 7,418(31.48) & 24,672(24.69) \\ \geq 8 \text { years } & 7,179(30.46) & 32,865(32.89)\end{array}$

Area of residence $(165,113)$

$\begin{array}{lccc}\text { Urban } & 32,049(95.57) & 119,150(90.56) & <0,001 \\ \text { Rural } & 1,301(3.88) & 11,406(8.67) & \\ \text { Periurban } & 186(0.55) & 1,021(0.78) & \\ \text { Institutionalization*** }(202,340) & & & \\ \text { No } & 35,878(92.63) & 152,237(93.05) & 0.004 \\ \text { Yes } & 2,853(7.37) & 11,372(6.95) & \end{array}$

Diabetes $(220,039)$

No $\quad 40,213(97.35) \quad 166,625(93.23)<0,001$

Yes $1,095(2.65) \quad 12,106(6.77)$

Alcoholism $(221,868)$

No

$34,161(82.60) \quad 149,930(83.06) \quad 0,027$

Yes

$7,194(17.40) \quad 30,583(16.94)$

*Number of valid observations. **Pearson's chi-squared test. ***prisoners. 
Table 2 Distribution of presentation and treatment characteristics of tuberculosis (TB) cases according to HIV status in Brazil, 2007-2011

\begin{tabular}{lccc}
\hline Characteristics $\left(\mathrm{N}^{*}\right)$ & $\begin{array}{c}\text { TB-HIV } \\
\mathrm{n}(\%)\end{array}$ & $\begin{array}{c}\text { TB only } \\
\mathrm{n}(\%)\end{array}$ & $P^{* *}$ \\
\hline
\end{tabular}

Type of Entry $(243,676)$

$\begin{array}{lccc}\text { New case } & 34,278(73.77) & 165,449(83.89) & <0,001 \\ \text { Relapse } & 4,418(9.51) & 12,235(6.20) & \\ \text { Return after default } & 4,681(10.07) & 10,471(5.31) & \\ \text { Unknown } & 240(0.52) & 245(0.12) & \\ \text { Transferred } & 2,849(6.13) & 8,810(4.47) & \\ \text { Uuberculin skin test (40,313) } & & & \\ \text { Negative } & 4,841(58.83) & 12,060(37.59) & <0,001 \\ \text { Positive } & 3,388(41.17) & 20,024(62.41) & \end{array}$

TB form $(243,670)$

Pulmonary

$29,738(64.00)$

Extra pulmonary

Pulmonary + Extra

pulmonary

X-Ray (208,432)

Negative

Suspicious of TB

Smear $(199,235)$

Negative
Positive
Culture $(60,671)$
Negative
Positive

Histopathologic

examination $(28,618)$

$\mathrm{AFB}^{* * *}$ positive

Suggestive

Not suggestive

DOT $^{* * * *}(226,736)$

No

Yes

Outcome $(215,884)$

$\begin{array}{lccc}\text { Cure } & 21,404(55.75) & 150,782(84.95) & <0,001 \\ \text { Default } & 7,247(18.88) & 17,474(9.84) \\ \text { Death from TB } & 2,700(7.03) & 4,296(2.42) \\ \text { Death from other causes } & 6,835(17.80 & 3,895(2.19) \\ \text { MDR-TB } & 206(0.54) & 1.045(0.59)\end{array}$

*Number of valid observations. **Pearson's chi-squared test. ${ }^{* * *}$ AFB: acid-fast bacilli.; ****OT: Directly Observed Therapy.

Individuals self-identified as black were more prevalent in the TB-HIV group (15.88\%) compared to the TB only group (12.81\%), $(\mathrm{p}<0.001)$ (Table 1$)$. The proportion of subjects with $<4$ years of education was higher in the TB only group (42.4\%) than TB-HIV group (38.0\%), $(\mathrm{p}<0.001)$. Most individuals lived in urban areas, though the proportion was slightly higher in the TB-HIV group $(95.57 \%$ vs $90.56 \%)(\mathrm{p}<0.001)$. Diabetes was less prevalent in TB-HIV group (2.65\%) compared to the TB only group $(6.77 \%)(\mathrm{p}<0.001)$. Alcoholism was similar between groups (17.40\% vs $16.94 \%$; $\mathrm{p}=0.027)$.

Table 2 describes the individuals according to characteristics of TB presentation. New TB cases were reported more among the TB only group (83.89\%) than the TBHIV group $(73.77 \%, \mathrm{p}<0.001)$. A greater proportion of the TB group $(62.41 \%)$ had a recorded positive tuberculin skin test compared to the TB-HIV group (41.17\%; $\mathrm{p}<$ 0.001). Prevalence of both pulmonary and extrapulmonary $\mathrm{TB}$ in the same individual was more prevalent in the TB HIV group $(11.90 \%$ vs $2.68 \%, \mathrm{p}<0.001)$. An $\mathrm{X}$-ray suggestive for TB was found in $86.60 \%$ of the TB-HIV group and $94.0 \%$ of the TB only group $(\mathrm{p}<0.001)$. On the other hand, smear and culture positivity were more prevalent among the TB only group $(69.34 \%$ vs $52.22 \%, \mathrm{p}<0.001)$ and $(60.95 \%$ vs $59.24 \%, \mathrm{p}<0.001)$, respectively (Table 2$)$.

The histopathologic examination had a higher proportion of AFB positive in the TB-HIV group compared with the TB only group $(46.91 \%$ vs $31.93 \%, \mathrm{p}<0.001)$. DOT was greater among the TB only group $(53.45 \%$ vs $38.32 \%, \mathrm{p}<0.001)$ and cure was markedly better as well $(84.95 \%$ vs $55.75 \%$; $\mathrm{p}<0.001)$ (Table 2 ).

The hierarchical multivariate model (Table 3) showed that individuals aged 20 to 39 years and 40 to 59 years were more likely to be TB-HIV coinfected compared to individuals $<20$ years of age (OR $=4.82,95 \%$ CI 4.34-5.36 and $\mathrm{OR}=3.67,95 \% \mathrm{CI} 3.30-4.09)$. Individuals $>60$ years of age did not have higher TB-HIV co-infection compared to those $<20$ years of age. The odds were greater for blacks to be TB-HIV (OR $=1.08,95 \%$ CI 1.04-1.13) and for those with school level between 4-7 years $(\mathrm{OR}=1.13,95 \% \mathrm{CI}$ 1.19-1.28). Living in rural area was protective of being co-infected $(\mathrm{OR}=0.44,95 \% \mathrm{CI} 0.41-0.48)$, as well as having diabetes $(\mathrm{OR}=0.45,95 \% \mathrm{CI} 0.40-0.50)$.

Patients diagnosed with TB after returning after default were more likely to be co-infected $(\mathrm{OR}=2.65,95 \%$ CI 1.13-6.25). Both pulmonary and extrapulmonary TB in the same individual were more likely to be reported as TB - HIV (OR $=2.80$, 95\% CI 1.56-5.02). TB-HIV coinfected patients were less likely to have a positive smear result $(\mathrm{OR}=0.55,95 \% \mathrm{CI} 0.32-0.95)$, but more likely to have a suggestive histopathologic examination $(\mathrm{OR}=2.15$, 95\% CI 1.13-4.07).

Finally, TB-HIV patients were more likely to get unfavorable results of tuberculosis treatment including default $(\mathrm{OR}=2.79,95 \%$ CI 2.45-3.18), death from $\mathrm{TB}(\mathrm{OR}=3.64$, 95\% CI 2.92-4.53) and death from other causes $(\mathrm{OR}=7.93$, 95\% CI 6.66-9.43). 
Table 3 Hierarchical* multivariate analysis of the association of tuberculosis by HIV status

\begin{tabular}{|c|c|c|c|c|}
\hline & \multicolumn{2}{|c|}{ Characteristics } & \multirow{2}{*}{$\begin{array}{l}\text { OR** }^{* *} \\
\text { Ref. }\end{array}$} & \multirow[t]{2}{*}{$95 \% \mathrm{Cl}^{* * *}$} \\
\hline & Gender & Female & & \\
\hline \multirow[t]{14}{*}{ Level 1} & & Male & 1,06 & $1.03-1.10$ \\
\hline & Age & $<20$ years & Ref. & \\
\hline & & 20-39 years & 4,82 & $4.34-5.36$ \\
\hline & & $40-59$ years & 3,67 & $3.30-4.09$ \\
\hline & & $\geq 60$ years & 1.04 & $0.92-1.18$ \\
\hline & Race & White & Ref. & \\
\hline & & Black & 1.08 & $1.04-1.13$ \\
\hline & & Browns & 0,77 & $0.75-0.80$ \\
\hline & & Other & 0,66 & $0.57-0.77$ \\
\hline & Schooling & $<4$ years & Ref. & \\
\hline & & 4-7 years & 1.23 & $1.19-1.28$ \\
\hline & & $\geq 8$ years & 0,96 & $0.92-1.00$ \\
\hline & Area of residence & Urban & Ref. & \\
\hline & & Rural & 0,44 & $0.41-0.48$ \\
\hline \multirow[t]{5}{*}{ Level 2} & & Periurban & 0,66 & $0.61-0.77$ \\
\hline & DOT**** & No & Ref. & \\
\hline & & Yes & 0.65 & $0.98-1.12$ \\
\hline & Institutionalization & No & Ref. & \\
\hline & & Yes & 1.07 & $1.00-1.15$ \\
\hline \multirow[t]{4}{*}{ Level 3} & Diabetes & No & Ref. & \\
\hline & & Yes & 0.45 & $0.40-0.50$ \\
\hline & Alcoholism & No & Ref. & \\
\hline & & Yes & 1.04 & $0.99-1.09$ \\
\hline \multirow[t]{17}{*}{ Level 4} & Type of entry & New case & Ref. & \\
\hline & & Relapse & 2.23 & $1.00-4.94$ \\
\hline & & $\begin{array}{l}\text { Return after } \\
\text { default }\end{array}$ & 2.65 & $1.13-6.25$ \\
\hline & & Unknown & 1 & - \\
\hline & & Transferred & 0.79 & $0.35-1.81$ \\
\hline & Tuberculin skin test & Negative & Ref. & \\
\hline & & Positive & 0.73 & $0.50-1.07$ \\
\hline & TB form & Pulmonary & Ref. & \\
\hline & & Extra pulmonary & 1.28 & $0.75-2.20$ \\
\hline & & $\begin{array}{l}\text { Pulmonary + Extra } \\
\text { pulmonary }\end{array}$ & 2.80 & $1.56-5.02$ \\
\hline & Smear & Negative & Ref. & \\
\hline & & Positive & 0.55 & $0.32-0.95$ \\
\hline & $\begin{array}{l}\text { Histopathologic } \\
\text { examination }\end{array}$ & AFB $^{* * * * *}$ positive & Ref. & \\
\hline & & Suggestive & 2.15 & $1.13-4.07$ \\
\hline & & Not suggestive & 0.71 & $0.37-1.34$ \\
\hline & X-Ray & Negative & Ref. & \\
\hline & & Suspicious of TB & 0.62 & $0.35-1.09$ \\
\hline
\end{tabular}

Table 3 Hierarchical* multivariate analysis of the association of tuberculosis by HIV status (Continued)

\begin{tabular}{lllll}
\hline Level 5 Outcome & Cure & Ref. & \\
& Default & 2.79 & $2.45-3.18$ \\
& Death from TB & 3.64 & $2.92-4.53$ \\
& Death from other & 7.93 & $6.66-9.43$ \\
& causes & & \\
& MDR-TB & 1.41 & $0.74-2.68$ \\
\hline
\end{tabular}

*The multivariate analyses: step 1 (Gender + age + schooling + race + Area of residence); step 2 (variables retained from step 1 + Institutionalization + DOT); step 3 (variables retained from step 2 + Diabetes); step 4 (variables retained from step 3 + treatment type+ TB form + Tuberculin Skin Test + smear + + culture + histopathologic examination $+X$ ray suspicious for TB); and step 5 (variables retained from step $4+$ outcome). ${ }^{* *}$ Adjusted odds ratio. ${ }^{* * *} \mathrm{Cl}$ : confidence interval. ${ }^{* * * *}$ DOT: Directly Observed Therapy. ${ }^{* * * * A F B}$ : acid-fast bacilli.

Since $43 \%$ of subjects with TB were excluded due to missing information of HIV status, we analyzed the treatment outcome (cure, default, death from TB, death from other causes and MDR TB) for HIV status. TB treatment outcomes were best for those who were known to be HIV negative and worst for those known to be HIV positive (data not shown). On the other hand, TB treatment outcomes for those in whom an HIV test was requested but the result was not available were better than those in whom the test was not done. In a multinomial analysis, considering cure as the reference group and comparing with HIV status (negative, positive, test requested but no result recorded and test not done) showed that death from TB presented an odds ratio of 1.48 with HIV positivity (95\% CI 1.43-1.53), whereas the default was 1.07 (95\% CI 1.04-1.10) Table 4.

\section{Discussion}

The prevalence of TB - HIV co-infection reported by SINAN was $19 \%$ among TB patients $\geq 15$ years of age with known HIV status. Co-infection was associated with being male, black, low level of education, living in an urban area and being between the ages of 20-59 $[4,10,18,19]$. These characteristics demonstrate the social characteristics of HIV-TB co-infection. The same epidemiological profile has been described in several studies in Brazilian cities $[4,20,21]$. These findings have been associated with the lifestyle of young adults often associated with lack of awareness of their vulnerability, exposing them to the HIV virus and tuberculosis [22].

Those socio-demographic characteristics strongly influenced the proportion of TB-HIV co-infection. Since the beginning of the new century, the AIDS epidemic in Brazil has reached new population groups and cities where it had not been previously reported, affecting the less privileged social segments in the country $[3,21,23]$. Such populations have historically been plagued with high TB rates; therefore, 
Table 4 TB treatment outcomes by HIV status in Brazil, 2007-2011

\begin{tabular}{ccccc}
\hline Outcome & \multicolumn{3}{c}{ HIV status } \\
\cline { 2 - 5 } & Negative & Positive & $\begin{array}{c}\text { Test requested but no } \\
\text { result recorded }\end{array}$ & Test not done \\
Cure & $\mathbf{n}(\%)$ & $\mathbf{n}(\%)$ & $\mathbf{n}(\%)$ & $\mathbf{n}(\%)$ \\
Default & $150,782(84.95)$ & $21,4(55.75)$ & $24,26(77.83)$ & $91,31(73.99)$ \\
Death from TB & $17,474(9.84)$ & $7,24(18.88)$ & $4,74(15.23)$ & $19,22(15.58)$ \\
Death* & $4,296(2.42)$ & $2,70(7.03)$ & $978(3.14)$ & $6,69(5.42)$ \\
MDR-TB & $3,895(2.19)$ & $6,83(17.80)$ & $1,03(3.31)$ & $5,75(4.66)$ \\
\hline
\end{tabular}

*Death from other causes.

the introduction of the AIDS epidemic has worsened the TB problem.

Co-infected patients were less likely to have prevalent diabetes in our study. It is important to highlight that TB patients with diabetes have demonstrated worse outcomes of TB treatment. A study carried out in Brazil using the Brazilian national surveillance system (SINAN) demonstrated that TB patients with diabetes were more likely to die of TB [24].

TB/HIV co-infected patients were less likely to be AFB positive than TB patients only which can be attributed to immunodeficiency. This result corroborate with other published studies which should indicate the need to develop more sensitive diagnostic techniques to confirm TB among HIV co-infected such culture. Another tool is a scoring system used to diagnose smear-negative pulmonary TB in children and adolescents, in HIV-infected adults suspected of having smear negative pulmonary TB. A study conducted in Brazil from a cohort of 2,382 HIVinfected adults [25], 1276 were investigated and 128 were diagnosed with pulmonary TB. The scoring system of the Brazilian Ministry of Health for the diagnosis of pulmonary $\mathrm{TB}$ in children and adolescents was adapted by the authors of the present study for HIV-infected adults and presented a good capacity for discriminating patients who did not have pulmonary TB, in the studied population.

The treatment of co-infected TB - HIV patients is difficult. Patients with TB require long-term treatment with various medications. For patients with TB-AIDS, adherence with the treatment regimen is difficult due to the extra burden of drug taking, resulting in higher default rate as showed in our study [26-28]. Because of this difficulty and poor adherence to tuberculosis treatment, new strategies for monitoring treatment should be devised, taking into account the characteristics of the co-infection as recommended by Brazilian National Tuberculosis Control. However, in our study the TB - HIV subjects were less likely to be covered under the DOT, although it was not statistically significant. This retention in DOT for TB/HIV co-infected patients was poor in relation to available AIDS and TB treatment models in Brazil. In addition, in some Brazilian cities there is no encouragement for patients on HAART to receive treatment supervision in the community such food vouchers and transportation subsidies.

We also found similar results as other studies [3,9,26], indicating that co-infected patients were more likely to have unfavorable treatment outcomes (default and death from TB). The explanation of this unfavorable outcome in our study is not easy. First, CD4 count is related to the severity and clinical presentation of tuberculosis in co-infection, extrapulmonary and disseminated as observed in our study. Second, among co-infected patients, mortality is commonly related to delayed diagnosis of TB because some HIV-infected individuals postpone seeking health care in order to avoid receiving an AIDS diagnosis [10]. As we can see HIV status plays an important role in TB treatment outcome. However, for $43 \%$ of patients reported in SINAN during the study period, HIV status was unknown. This information is similar to what was found by a study [9] carried out in Brazil, from 2003 to 2008. That study showed that the group with unknown HIV status showed intermediate outcomes between the groups above (TB only and TB-HIV), suggesting that this group includes some with HIV infection.

We analyzed the epidemiological profile of tuberculosis patients with unknown HIV status with patients with known status in our study period, and we observed that the group with unknown HIV status shared more similar socio-demographic characteristics with the TBHIV group, although some clinical characteristics of disease were more similar with TB only group as TB form (pulmonary form was more prevalent, data not shown). These facts, coupled with what the study [9] cited above points out, leads us to believe that the group of patients for which we have no known HIV status is a mix of HIV positive and negative individuals. We cannot quantify or identify the direction of the bias our results may have suffered, but as already mentioned, this is a limitation that is inherent to operational research using secondary data such as national disease reporting systems. 
Our study has some other limitations. Firstly, the proportion of missing data for some variables was quite significant. Nevertheless, our large sample size still allowed us to maintain high statistical power for all analyses, but not accounting for potential biases. Secondly, we did not have access to information about antiretroviral therapy (ART) history or CD4 count among our group of HIV co-infected patients. Therefore, we did not know if the patients were diagnosed with TB prior to, concomitant with, or after the diagnosis of HIV infection.

\section{Conclusions}

Our analysis provides better understanding of the sociodemographic and clinical differences between HIV and non-HIV related TB in Brazil, providing evidence for developing targeted interventions directed towards reducing both infections in high risk groups. We recommend that the Brazilian National Tuberculosis Control Plan, which currently recommends all patients diagnosed with TB be tested for HIV, be strengthened through better integration and communication between AIDS and TB programs.

\section{Competing interests}

The author(s) declare that they have no competing interests.

\section{Authors' contributions}

All authors made substantive intellectual contributions to the study and read and approved the final manuscript. TNP designed the study. AEM and DAS, MNS, JEG critically reviewed and revised the manuscript. ESD and FMS, LKFS analysed the data and revised the manuscript. ELM was involved in the acquisition of the data, analysis and interpretation of data, and revision of the manuscript. All authors read and approved the final manuscript.

\section{Acknowledgements}

This study was supported by CNPq/Brazil edital Doenças negligenciadas 2012 and Universal 2010, the U.S. National Institutes of Health, undercontract ICOHRTA 5 U2R TW006883-02, and FAPES (Fundação de Amparo à Pesquisa do Espírito Santo).

\section{Author details}

'Lab-Epi UFES - Laboratório de Epidemiologia, Universidade Federal do Espírito Santo, Av. Marechal Campos, 1468- Maruípe, Vitória, ES, Brazil. ${ }^{2}$ School of Nursing, Federal University of Espírito Santo, Espírito Santo, Brazil. ${ }^{3}$ Post-Graduate Program in Infectious Diseases, Federal University of Espírito Santo, Espírito Santo, Brazil. ${ }^{4}$ Post-Graduate Program in Public Health, Federal University of Espírito Santo, Espírito Santo, Brazil. ${ }^{5}$ TB National Consultant, Pan American Health Organization, São Paulo, Brazil. ${ }^{6}$ Department of Public Health, University of Brasilia, Federal District, Brazil. ${ }^{7}$ Center for Tuberculosis Research, Johns Hopkins University School of Medicine, Baltimore, MD, USA.

Received: 16 March 2014 Accepted: 17 July 2014

Published: 28 July 2014

\section{References}

1. World Health Organization: Global Tuberculosis Control 2011: WHO Report 2011. Geneva: WHO; 2011.

2. de Oliveira GP, Torrens AW, Bartholomay P, Barreira D: Tuberculosis in Brazil: last ten years analysis - 2001-2010. Braz J Infect Dis 2013, 17(2):218-233.

3. Guimarães RM, Lobo Ade P, Siqueira EA, Borges TF, Melo SC: Tuberculosis, HIV, and poverty: temporal trends in Brazil, the Americas, and worldwide. J Bras Pneumol 2012, 38(4):511-517.

4. Muniz JN, Ruffino-Netto A, Villa TC, Yamamura M, Arcencio R, Cardozo-Gonzales RI: Epidemiological aspects of human immunodeficiency virus/tuberculosis co-infection in Ribeirão Preto, Brazil from 1998 to 2003. J Bras Pneumol 2006, 32(6):529-534

5. Daley CL, Small PM, Schecter GF, Schoolnik GK, McAdam RA, Jacobs WR Jr, Hopewell PC: An outbreak of tuberculosis with accelerated progression among persons infected with the human immunodeficiency virus. An analysis using restriction-fragment-length polymorphisms. N Engl J Med 1992, 326(4):231-235.

6. Corbett EL, Watt CJ, Walker N, Maher D, Williams BG, Raviglione MC, Dye C. The growing burden of tuberculosis: global trends and interactions with the HIV epidemic. Arch Intern Med 2003, 163(9):1009-1021.

7. Braun MM, Coté TR, Rabkin CS: Trends in death with tuberculosis during the AIDS era. JAMA 1993, 269(22):2865-2868.

8. Santos Filho ET, Gomes ZMS: Estratégias de controle da tuberculose no Brasil: articulação e participação da sociedade civil. Revista Saúde Pública 2007, 41(1):111-116.

9. Sanchez M, Bartholomay P, Arakaki-Sanchez D, Enarson D, Bissell K, Barreira D, Harries A, Kritski A: Outcomes of TB treatment by HIV status in national recording systems in Brazil, 2003-2008. PLoS One 2012, 7(3):e33129.

10. Prado TN, Caus AL, Marques M, Maciel EL, Golub JE, Miranda AE: Epidemiological profile of adult patients with tuberculosis and AIDS in the state of Espírito Santo, Brazil: cross-referencing tuberculosis and AIDS databases. J Bras Pneumol 2011, 37(1):93-99.

11. Rieder HL, Cauthen GM, Bloch AB, Cole CH, Holtzman D, Snider DE Jr, Bigler WJ, Witte JJ: Tuberculosis and acquired immunodeficiency syndrome-Florida. Arch Intern Med 1989, 149(6):1268-1273.

12. Sunderam G, McDonald RJ, Maniatis T, Oleske J, Kapila R, Reichman LB: Tuberculosis as a manifestation of the acquired immunodeficiency syndrome (AIDS). JAMA 1986, 256(3):362-366.

13. Cerqueira ACB, Sales CMM, Lima R, Silva MZ, Vieira RCA, Brioschi AP, Moreira-Silva SF, Lima LHM, Miranda AE, Maciel ELN: Completude do sistema de informação de agravos de notificação compulsória de gestante HIV positivo entre 2001 e 2006, no Espírito Santo, Brasil. UFES Rev Odont 2008, 10(1):33-37.

14. Brasil: Sistema de Informação de Agravos de Notificação. Brasília: Ministério da Saúde; 2004.

15. Fuchs SC, Victora CG, Fachel J: Modelo hierarquizado: uma proposta de modelagem aplicada à investigação de fatores de risco para diarréia grave. Rev Saude Publica 1996, 30:168-178

16. Victora CG, Huttly SR, Fuchs SC, Olinto MT: The role of conceptual frameworks in epidemiological analysis: a hierarchical approach. Int J Epidemiol 1997, 26:224-227.

17. Maciel EL: Determinantes Sociais da Tuberculose: Elementos para a Ação. Promoção da Saúde na Diversidade Humana e nos Itinerários Terapêuticos. Campinas: Saberes; 2012

18. Aerts $D$, Jobim $R$ : The epidemiological profile of tuberculosis in southern Brazil in times of AIDS. Int J Tuberc Lung Dis 2004, 8:785-791.

19. Lazarus JV, Olsen M, Ditiu L: Tuberculosis-HIV co-infection: policy and epidemiology in 25 countries in the WHO European region. HIV Med 2008, 9:406-414

20. Carvalho LGM, Buani AZ, Zöllner MSAC, Scherma AP: Co-infection with mycobacterium tuberculosis and human immunodeficiency virus: an epidemiological analysis in the city of Taubaté, Brazil. J Bras Pneumol 2006, 32(5):424-429.

21. Silveira JM, Sassi RA, de Oliveira Netto IC, Hetzel JL: Prevalence of and factors related to tuberculosis inseropositive human immunodeficiency virus patientsat a reference center for treatment of human immunodeficiency virus in the southern region of thestate of Rio Grande do Sul, Brazil. J Bras Pneumol 2006, 32(1):48-55.

22. Santos MLSG, Ponce MAZ, Vendramini SHF, Villa TCS, Santos NSGM, Wysocki AD, Kuyumijian FG, Gazetta CE: The epidemiological dimension of TB/HIV coinfection. Rev Latino-am Enfermagem 2009, 17(5):683-688. setembro outubro.

23. Pawlowski A, Jansson M, Sköld M, Rottenberg ME, Källenius G: Tuberculosis and HIV co-infection. PLOS Pathog 2012, 8(2):e1002464.

24. Reis-Santos B, Locatelli R, Horta BL, Faerstein E, Sanchez MN, Riley LW, Maciel EL: Socio-demographic and clinical differences in subjects with tuberculosis with and without diabetes mellitus in Brazil - a multivariate analysis. PLoS One 2013, 8(4):e62604.

25. Coimbra I, Maruza M, Albuquerque Mde F, Batista JD, Braga MC, Moura LV, Miranda-Filho DB, Montarroyos UR, Lacerda HR, Rodrigues LC, Ximenes RA: Validating a scoring system for the diagnosis of smear-negative pulmonary tuberculosis in HIV-infected adults. PLoS One 2014, 9(4): e95828. 
26. Rodrigues ILA, Monteiro LL, Pacheco RHB, Silva SED: Abandono do tratamento de tuberculose em coinfectados TB/HIV. Revista da Escola de Enfermagem da USP 2010, 44(2):383-387.

27. Neves LAS, Reis RK, Gir E: Adesão ao tratamento por indivíduos com a co-infecção HIV/tuberculose: revisão integrativa da literatura. Revista da Escola de Enfermagem da USP 2010, 44(4):1135-1141.

28. Fenner L, Gagneux S, Janssens J-P, Fehr J, Cavassini M, Hoffmann M, Bernasconi E, Schrenzel J, Bodmer T, Böttger EC, Helbling P, Egger M: Tuberculosis in HIV-negative and HIV-infected patients in a low-incidence country: clinical characteristics and treatment outcomes. PLoS One 2012, 7(3):e34186.

doi:10.1186/1471-2334-14-415

Cite this article as: do Prado et al:: Factors associated with tuberculosis by HIV status in the Brazilian national surveillance system: a cross sectional study. BMC Infectious Diseases 2014 14:415.

\section{Submit your next manuscript to BioMed Central and take full advantage of:}

- Convenient online submission

- Thorough peer review

- No space constraints or color figure charges

- Immediate publication on acceptance

- Inclusion in PubMed, CAS, Scopus and Google Scholar

- Research which is freely available for redistribution 